\title{
APLASIA CUTIS CONGENITA OF THE SCALP
}

\author{
Joacil C. da Silva', João Paulo C. de Almeida², Suzana Serra', Igor Faquini', \\ Saul Quinino', Francisco Nêuton de O. Magalhães', Hildo Azevedo-Filho ${ }^{3}$
}

Aplasia cutis congenita (ACC) is an uncommon disorder that presents as a focal defect of the skin at birth, frequently involving the midline over the skull vertex $(70 \%)$, but it may affect any region of the body ${ }^{1-7}$. Since 1767, about 500 cases have been reported in medical literature $^{6-12}$. The skin lesions are quite variable, ranging from absence of skin to a complete lack of subcutaneous tissue, bone or even the dura, ${ }^{4,1,13,14}$. The ACC can be isolated or associated with other malformations in a genetic syndrome, like Adams-Oliver syndrome ${ }^{12,13}$. There are no exact etiologies for ACC, but some conditions have been associated to it like intrauterine vascular ischemia, amniotic adherences and viral infections ${ }^{13,14}$. Teratogenic medications like metimazole and misoprostol have been proposed as causes of ACC ${ }^{9,2,14}$.

There is no consensus about the ideal treatment for the ACC, which is probably related to the low prevalence and incidence of this condition. The treatment options are conservative management or surgical correction, based on the clinical picture presented by each patient.

\section{CASE}

A female infant was born preterm ( 35 weeks) by cesarian section, after one complicated first pregnancy of her adolescent mother. The pregnant had used misoprostol from the third until the sixth month of pregnancy for abortion. No infectious diseases, use of intravenous drugs, alcohol or tobacco were observed in the gestational period. Parents did not have any familiar link. Two prenatal ultrasounds studies ( 3 and 8 months) had been reported as normal.

The infant birth weight was of $2655 \mathrm{Kg}$ and the height was 46 $\mathrm{cm}$ with good clinical conditions. There was no history of congenital defects in the family. One large skin defect measuring approximately $10 \times 2 \mathrm{~cm}$ in the frontal area of the scalp with no subjacent bone and exposure of the dura-mater was diagnosed after delivery.

She was referred to our neurosurgical department a few hours after birth. Once she presented in a good clinical status, early surgical intervention in order to protect against infections was made. Informed consent was obtained from the family and the patient underwent the surgical procedure She underwent surgical treatment in the second day of life. We performed undermining of the surrounding scalp and then a primary closure of the cutaneous defect was realized (Figs 1 and 2). The procedure was uneventful and without necessity of blood transfusion. The transfontanel ultrasound was normal and further physical examination revealed no additional abnormalities.

\section{DISCUSSION}

We describe a case of ACC caused by the ingestion of misoprostol (Cytotec). The misuse of this medication to promote self-induced abortion is common, specially in some developing countries like Brazil where abortion is not allowed (except in cases of maternal risk or rape). ACC has been reported to be caused by several teratogens ${ }^{1,2,7}$. Other authors have described the association between misoprostol and $\mathrm{ACC}^{7}$. Several drugs may be linked to $A C C$, like cocaine, which can lead to placental vasoconstriction or fetal vascular disruption causing cranial defects and central nervous system (CNS) anomalies. The use of benzodiazepines has been asssociated with ACC as described by Martínez-Lage et $\mathrm{al}^{7}$. Some angiotensinconverting enzyme inhibitors and methrotexate also may be associated with CNS malformations and $\mathrm{ACC}^{1,2}$. In this case, the prolonged use of misoprostol ( 3 months) without successful abortion and the absence of other CNS anomalies represents an uncommon pattern. The ultrasounds were negative which can be justified by the fact that it is an operator-dependent exam. Dror et al. found that a distinct amniotic fluid acetylcholinesterase band and elevated levels of alpha-fetoprotein could be applied as markers for $\mathrm{ACC}^{16}$, but such markers were not used in our case.

There is a lot of controversy in the literature about the treatment of ACC and the timing of surgery. The management can be conservative, surgical or combined. Some factors should be considered before choosing one of

\section{APLASIA CUTIS CONGÊNITA DO ESCALPO}

Department of Neurosurgery, Hospital da Restauração, Recife PE, Brazil: 'Department of Neurosurgery, Hospital da Restauração, Recife PE, Brazil; ${ }^{2}$ Medical School, Federal University of Ceará, Fortaleza CE, Brazil; ${ }^{3}$ Professor and Chairman, Department of Neurosurgery, Hospital da Restauração, Recife PE, Brazil .

Received 29 May 2008, received in final form 21 July 2008. Accepted 29 July 2008.

Dr. João Paulo Cavalcante de Almeida - Rua Paulo Morais 130 - 60175-175 Fortaleza CE - Brasil. E-mail: jpaulocavalcante@yahoo.com.br 

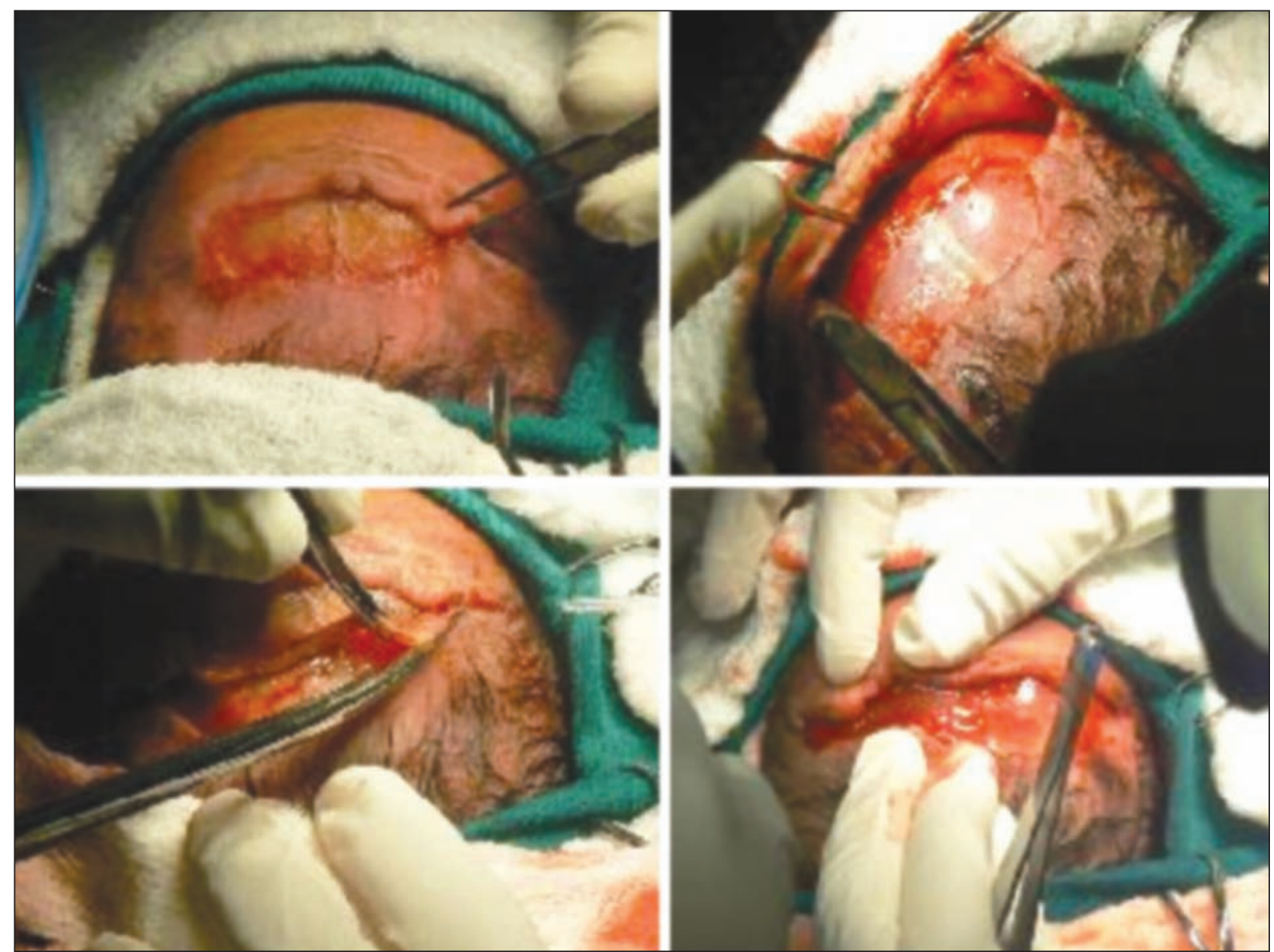

Fig 1. Skin and bone defects in the frontal region with dural exposition. The surgical procedure consisted of undermining of surrounding scalp and primary closure of the skin.
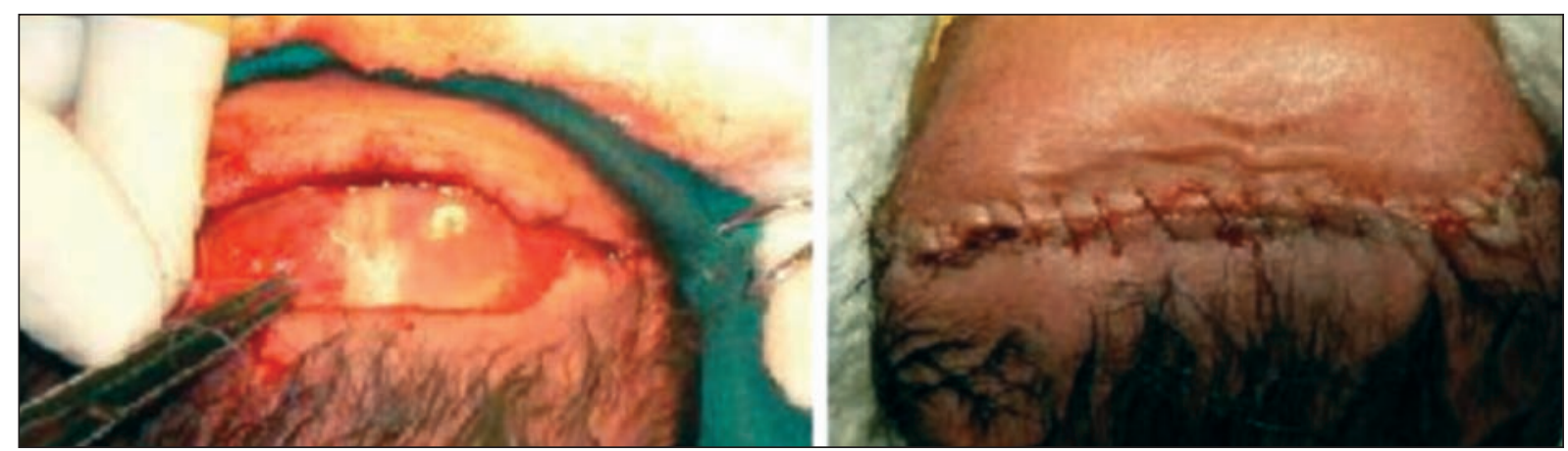

Fig 2. Skin closure and final aspect at the end of surgery.

these therapeutic options, and the two majors are the site of the lesion and the patients clinical status. Some authors have described the urgent surgical intervention for extensive defects overlying the sagittal sinus to prevent hemorrhage and lethal infections ${ }^{4,6-8,16-18}$. The size of the skin lesion should be considered too and defects smaller than $1 \mathrm{~cm}$ may be expected to heal spontaneously ${ }^{6}$, if they obviously are superficial ones. The use of soaked wound dressings is common and some reports of grafting and bi- ological dressings during the healing period have achieved variable success ${ }^{7,14,9,20}$. The re-epithelization may produce a hipertrophic or atrophic scar ${ }^{14}$. Deep defects, like those with brain exposure, have a higher risk of vascular and infectious complications, therefore, agressive management with surgical repair is mandatory. In larger defects it might be necessary to cover the donor area with split skin grafts, to allow for the development of a large flap to cover the defect. 
In our case we found by clinical examination that the baby was in good conditions, and the local of the skin defect allowed the early surgical intervention with the objective of avoiding infection and protection of the brain.

$A C C$ is a rare disorder with no exact etiology, but in this case clearly linked to the inappropriate use of misoprostol which is a very common practice for abortion in several developing countries. The early reconstruction of the scalp is the treatment option in a subgroup of patients, clinically essential in order to avoid infections in newborn.

\section{REFERENCES}

1. Frieden IJ. Aplasia cutis congenita: a clinical review and proposal for classification. J Am Acad Dermatol 1986;14:646-660.

2. Lambert J, Goulaert P, Naeyaert JM. What syndrome is this? Pediatr Dermatol 1997;14:330-332

3. Lassman LP, Sims DG. Congenital midline scalp and skull defects. Arch Dis Child 1950;50:958-960

4. Croce EJ, Purohit RC, Janovski NA. Congenital absence of skin (aplasia cutis congenita). Arch Surg 1973;106:732-734.

5. Fisher M, Schneider R. Aplasia cutis congenita in three successive generations. Arch Dermatol 1973;108:252-253.

6. Bexkmans SJA, Mulder JW. Aplasia cutis of the scalp: a report of two cases. Eur J Plast Surg 2000;23:245-247.
7. Martínez-Lage JF, Almagro MJ, Hernández FL, Poza M. Aplasia cutis congenita of the scalp. Childs Nerv Syst 2002;18:634-637.

8. Lavine D, Lehman A, Thomas R. Congenital scalp defect with thrombosis of the sagittal sinus. Plast Reconstr Surg 1978;61:599-602.

9. Lynch PJ, Kahn EA. Congenital defects of the scalp. A surgical approach to aplasia cutis congenital. J Neurosurg 1970;33:198-202.

10. Muakkassa KF, King RB, Stark DB. Nonsurgical approach to congenital scalp and skull defects. J Neurosurg 1982;56:711.

11. Demmel U. Clinical aspects of congenital skin defects: congenital skin defects on the head of the newborn. Eur J Pediatr 1975;21:21-50.

12. Oliveira RS, Lins-Neto AL, Farina J. Aplasia cutis congenita of the scalp: is there a better treatment strategy? Childs Nerv Syst 2005;22:1072-1079.

13. Adams FH, Oliver CP. Hereditary deformities in man due to arrested development. J Hered 1945; 36:3-7.

14. Evers ME, Steijlen PM, Hamel BC. Aplasia cutis congenital and associated disorders: an update. Clin Genet 1995;47:295-301.

15. Fagan LL, Harris PA, Coran AG, Cywes R. Sporadic aplasia cutis congénita . Pediatr Surg Int 2002;18:545-547.

16. Dror Y, Gelman-Kohan Z, Hagai Z, Juster-Reicher A, Cohen RN, Mogilmer B. Aplasia cutis congenita, elevated alpha-fetoprotein, and a distinct amniotic fluid acetylcholinesterase electrophoretic band. Am J Perinatol 1994;1:149-152.

17. Peer LA, Duyn JV. Congenital defect of the scalp: report of a case with fatal termination. Plast Reconstr Surg 1948;3:722-723.

18. Sargent LA. Aplasia cutis congenita of the scalp. J Ped Surg 1990;25(12): 1211-1213.

19. Bailie FB. Aplasia cutis congenita of neck and shoulder requiring a skin graft: a case report. Br J Plast Surg 1983;36:72-74.

20. Blunk K, Quan V, Carr C. Aplasia cutis congenita: a clinical review and associated defects. Neonatal Network 1992;11:17-27. 